\title{
Russell, Experience, and the Roots of Science
}

\section{A. C. Grayling}

\section{I}

Empiricism is the family of theories which in one or another way locate the source or at very least the test of contingent knowledge in experience - specifically, in sensory experience. More circumstantially: it is the family of theories which variously require experiential grounds for concepts to have content or applicability, or for expressions in a given language to have sense. In these versions of a formulation, due allowance is made for the thought that the content of perceptual states, suitably construed, are to be considered the occasion or basis for certain kinds of fundamental judgments from which, together with other premises, our less fundamental judgments about the world (or things other than the content of those states of sensitivity themselves) can be inferred.

In a qualified sense of this broadly characterised position, Russell was an empiricist, and his epistemology remained in that qualified sense empiricist throughout its development. But he was also critical of certain forms of empiricism, and the focus of his own concerns were such that his aims in formulating epistemological views, and his evolving attempts to realise these aims in detail, are not straightforwardly traditional. The chief reason for this is that his overarching concern was the question of how science is related to subjective experience, beginning (in the work done in 1911-14) with attempts to show how the fundamental concepts of physics can be derived from experience, and ending (in 1948) by shifting attention to the question of the non-empirical features of knowledge-acquisition required for bridging the gap between experience and science.

In these aims for epistemology Russell was remarkably consistent throughout the period 1911- 48, which is to say, from the time he finished work on the first edition of PM until his last major philosophical book, HK. His concern was not the traditional epistemological one of showing that knowledge is justified by experience, where this task is typically specified by a response to sceptical arguments. Russell was thoroughly Lockean in his attitude to the theory of knowledge, in the sense that he did not think scepticism a serious option, and therefore did not waste time attempting to rebut it. Rather, he conceived epistemology's proper task as one of displaying how one gets from sense experience to science. For Russell this was an explanatory, not a justificatory, task.

In the cluster of texts addressing the question of the experience-science relation in the immediate post-PM period, Russell describes his aim as showing how physics is 'verified' by observation and experiment - by which he meant: having its predictions confirmed by these means. Given that all that can be directly observed are the data of sense, he saw the question as one of explaining the correlation of the contents of the physical world with the data of sensory experience by which they are alone verifiable. He did not put the point by saying that claims about the content of the physical world are verified (still less justified) by sensory experience; and this is neither an accidental nor a merely historically-conditioned trick of formulation. It is a feature of robust realism not to construe the point of epistemology as being the justification of knowledgeclaims, but as being an explication of the relation between what the claims are about and the nature of experience. 'Justifying science by grounding it in experience' and 'showing how physics succeeds in being an empirical science, based on observation and experiment' are two different aims, and Russell's was the latter.

In PP, which gives the outlines of Russell's early view in popular form, the project begins by adopting the Cartesian air of a justificatory, scepticism-rebutting enterprise. The same is true of the discussion in IMT and Russell's replies in Schilpp. But that was because Russell saw the principal task of showing how experience and science relate as the obverse of the coin whose reverse is the more familiar form of discussion in which experience is invoked as the ground of knowledge. Because Russell assumed throughout that science is (or at least is on the way to discovering) the truth about the world (and his considered views consistently respected this assumption), he did not see epistemology's task to be the defence of science against doubt, but instead to be the demonstration of how finite human subjectivity acquires knowledge of the objective reality which science describes. In showing this, it also shows that the degree of certainty possible in contingent knowledge is less than absolute. In this sense, Russell was happy to concede something to scepticism without being much troubled by it; after all - so in effect he thought - what else is to be expected from contingent empirical knowledge.

In the earlier phases of his endeavour Russell saw the task of technical philosophy (philosophy conceived as logic; in fact, though, this aspect of Russell's endeavour is more accurately described as metaphysics) as principally being one of showing how the fundamental concepts of science (as he then took them to be) space, time, causality and matter can be constructed, and in his view this was a more important and more interesting matter than the epistemological question of how one relatively insignificant fragment of reality humanity - manages more or less successfully to represent the rest of reality to itself. It is easy to overlook the fact that these two of Russell's tasks - the logical construction of the then-conceived fundamental scientific concepts, and the question of how finite subjective experience connects with scientific knowledge are different, although of course they impinge upon one another at most points. But Russell's attention came rapidly to focus almost exclusively on the epistemological task, to which the larger part of his strictly philosophical writings after 1911 were addressed.

What changed over time in Russell's thought after 1911 was not his epistemological aim, but the strategies he successively adopted to try to achieve it. Perhaps because science itself dramatically altered the question of which concepts are fundamental to it (space and time had become space-time in Einstein's theories, and matter had vanished in the wake both of them and quantum theory), Russell ceased to look for a logical 
construction of these specific concepts. Indeed, he abandoned the logical constructivist programme long before the likes of Carnap and Goodman attempted them, and before Wisdom had shown that getting the world out of sense-data without residue is impossible.

The continuities and developments in Russell's relation-of-sense-to-science project are well displayed as the similarities and contrasts between his description of the project's aims, and of the methods to be employed in carrying it out, in the 1911-14 writings and HK in 1948. Commentators generally take at face value Russell's own claim, in MPD, that in AMi (1921) he abandoned not just the nomenclature of the sense-datum theory but what it was trying to achieve; and this is taken among other things to mark a more expressly 'neutral monist' turn as the metaphysical basis of his epistemological efforts until, in his very late work, another and final shift of perspective occurs, this time away from efforts to carry out the original project and towards the task of identifying the non-empirical supplements which, by that stage, he saw as the chief interest in discussing the bridge over the experience-science gap. But in fact it can be shown that despite the asseverations of MPD and the apparent elimination of the subject in AMi (courtesy of Russell's by then further developed conception of the 'neutral monist' stance), the underlying theme of specifying the connections between experience and science remained. Of course, from the period of AMi onward Russell changed the terms of the relation at issue dramatically; acquaintance vanished, and was replaced (to begin with) by 'noticing' (experiential salience) and successor conceptions. Acquaintance and the subject seemed to go so intimately together that their departure appeared jointly necessary; but it is no surprise to find the epistemic subject still in view in HK, having been merely in disguise in the interim.

The purpose in what follows is accordingly to illustrate, by way of an account of the development of Russell's project, the remarkable consistency of aim it displays. I do this by tracing the project's history, chiefly to establish an accurate characterisation of it, but also to provide a corrective to the impression that in epistemology Russell merely offered a sequence of ad hoc moves in response to a problem which has since been understood, but even then was already beginning to be recognised, as misconceived, viz. the endeavour to erect a justificatory theory of knowledge on the flawed Cartesian grounds of deriving certainty from the private data of experience. But to repeat: Russell's task was, interestingly and significantly, different from that; he did not see epistemology as a justificatory enterprise aimed at refuting scepticism, but as a descriptive enterprise aimed at explaining the fact (which he did not question) that finite subjects attain scientific knowledge. He was thus a naturalist long before Quine or anyone else, despite rightly insisting, as later naturalists did not, that one cannot premise science in epistemology ; and he was far more consistent in his aims and principles than most (agreeing with Charles Broad) have allowed.

Certain corollaries attend the picture I offer. One is that Hylton misdescribes Russell's turn to epistemological themes after PM as involving 'considerable concessions to psychologism'. Whatever else the label means, 'psychologism' is at least the view that the objects of acquaintance and judgment (to use period Russellian terms for the purpose) cannot themselves be described independently of features attaching to them as a result of the psychological conditions of their apprehension. This is never Russell's claim, and indeed anything like it was expressly disavowed in his pre-PoM flight from idealism. Post-PM Russell was realist to excess, rather than psychologistic, in allowing a wider range of objective targets of acquaintance than a traditional empiricist would allow, embracing as it did both physical particulars and abstract entities of various kinds. So much is familiar. And this is not to deny that Russell's interests lay in connecting the content of psychological states (mental states of the subject-relatum in acquaintance and judgment) with the independent objects such states brought into the subject's ken; for, after all, it was the 'transition from sense to science' as he still called it at the end of his philosophical life (MPD 153) that was his focus, and this requires addressing the question of what and how much the psychological states of epistemic subjects can be said to give them of objective scientific truth.

A corollary of the consistency thesis which I here argue on Russell's behalf is that the celebrated derailment of Russell's project in TK, ascribed to Wittgenstein as a result of some (characteristically hyperbolic) remarks by Russell in a letter to Lady Ottoline Morrell, might not be quite what it seems; for in a footnote added to the text of 'On Knowledge by Acquaintance and Knowledge by Description' when this 1911 essay was reprinted in ML in 1917, Russell remarks of his multiple relation theory of judgment, 'I have been persuaded by $\mathrm{Mr}$ Wittgenstein that this theory is somewhat unduly simple, but the modification which I believe it to require does not affect [its fundamentals].' The same point occurs more fully in LLA where Russell discusses the difficulties faced by the theory, involving subordinate 'verbs'. He subsequently, somewhat without fanfare, abandoned the theory; but it is clear from the fact that he continued to the end with the larger project of clarifying the experience-science connection that he found his multiple relation theory of judgment to be inessential to it; and therefore the fact that Russell dismembered TK and left some parts of it unused is not the same as his abandoning the project in whose working out TK was a chapter.

II

A good way to begin is to observe the images Russell employs early and late in preparing readers for the epistemological task as he conceived it. In the Preface to HK he observes that the terms 'belief', 'truth', 'knowledge' and 'perception' all have imprecise common uses which will require progressive clarification as the enquiry proceeds. 'Our increase of knowledge, assuming that we are successful, is like that of a traveller approaching a mountain through a haze: at first only certain large features are discernible, and even they have indistinct boundaries, but gradually more detail becomes visible and edges become sharper.' Compare this to what Russell says in TK of the ambiguities of the words 'experience', 'mind', 'knowledge' and 'perception': 'The meanings of common words are vague, fluctuating and ambiguous, like the shadow thrown by a flickering street-lamp on a windy night; yet in the nucleus of this uncertain patch of meaning, we may find some precise concept for which philosophy requires a name' < which, Russell concludes, should best be the common expressions themselves, made suitably definite. Imagery aside, part of the method of both early 
and late epistemology is thus characterised as the same: clarification of concepts, on one familiar view the central task of analysis characteristic of 'analytic philosophy'. But Russell also took the view that analysis is only the propaedeutical part of the story; more important (so he early believed and hoped) was the constructive task of showing how complexes of various kinds - and not least, knowledge of complexes - can be constructed out of simples - early on, the simples with which we are acquainted. The constructive task is the one which ended in failure, and the changes in Russell's epistemology are a direct function of the difficulties met with in the course of the project, which he increasingly saw as insurmountable. The hope had been to couple analysis and synthesis, the first activity preparing the way for the second, reflecting Russell's early ambition, formed on a walk one day in Berlin in the 1890s, to link abstract and scientific knowledge into a grand synthesis.

The synthetic task failed, but one thing which did not change was the aim subserved by the method developed to carry it out. In TK Russell plunges straight into the task of analysing acquaintance, which he calls 'the simplest and most pervading aspect of experience', a dyadic relation (an important point, for cognate polyadic relations of higher order constitute something significantly different, namely, judgments) between a 'mental subject' and what turn out to be the catholically-conceived objects of its attitudes. This was to fulfil a promise implicit in the outline of a programme given in March 1911 in three lectures: the Aristotelian Society address 'Knowledge by Acquaintance and Knowledge by Description', and two lectures delivered in Paris, 'Le Realisme Analytique' and 'L'importance philosophique de la logistique'. In the first of these latter he reasserts his commitment to realism both in epistemology and as regards universals, and outlines the technique of analysis of complex into simples to which he there first applies the name 'logical atomism'. In that and the companion lecture he launches the work characteristic of the 1911-14 period, worked out in most detail in a series of papers < 'On Matter' (1912), 'The Relation of Sense-Data to Physics' and 'On Scientific Method in Philosophy' (1914), and 'The Ultimate Constituents of Matter' (1915; the three latter are reprinted in ML) < whose chief precipitate constitutes OKEW (1914). Notoriously, the project was first planned to result in TK; but the difficulties over the theory of judgment obliged Russell to dismantle the task into what he doubtless hoped would be more manageable components.

The project is sketched in a letter from Russell to Ottoline Morrell in October 1912. 'The sort of thing that interests me now is this: some of our knowledge comes from sense, some comes otherwise; what comes otherwise is called "a priori". Most actual knowledge is a mixture of both. The analysis of a piece of actual knowledge into pure sense and pure a priori is often very difficult, but almost always very important.' Russell had chosen both parts of the task: to trace the transition from sense to science, and to isolate the a priori elements of the latter and to axiomatise them, as a preparation for defining the central concepts (space, time, causality and matter itself). Arguably, the epistemological task came to seem pressing to Russell for the two reasons that whereas, at the outset, the business of defining the fundamental concepts of physics appeared to be a straightforward parallel to defining the fundamental concepts of arithmetic, it quickly transpired that the relation of sense to science was not easy to carry out, and moreover that it was a necessary preliminary to completing the task of logically constructing the concepts of physics from whatever primitive concepts could be discovered in the then fundamental areas of physics, electrodynamics and classical mechanics, together with the relations between them. The reason for the latter is that the empirical content of the primitives requires that they themselves be constructible from sensory experience, as required by the principle that everything we know must be anchored at last in acquaintance.

Russell accordingly deferred the attempt to construct science's central concepts to deal with the epistemological questions first. It is instructive to see how these, in their own right, came to seem to him problematic, given that his first sketch of them (in PP) was an optimistic one, in that it canvassed the traditional questions about the relation of experience to knowledge with a robust acceptance of the fallibility of such knowledge, and the presence in it of assumptions or principles themselves neither independently testable nor matters of logic alone.

\section{III}

In PP Russell introduced the label 'sense-data' to designate what is immediately known in sensation: particular instances in perceptual awareness of colours, sounds, tastes, smells and textures, each class of data corresponding to one of the five sensory modalities. Not only must sense-data be distinguished from acts of sensing them, they must also be distinguished from objects in space outside us with which we suppose them associated. Russell's primary question therefore was: what is the relation of sense-data to these objects?

Russell was not, as noted, concerned to address scepticism. His tack was to say that although sceptical arguments are strictly speaking irrefutable, there is nevertheless 'not the slightest reason' to suppose them true (PP p 17). Instead he assembles persuasive considerations in support of the view that having sensedata provides access to reasonable knowledge of things in space. First, we can take it that our immediate sensory experiences have a 'primitive certainty'. We recognise that when we register sense-data which we naturally regard as associated with, say, a table, we have not said everything there is to be said about the table. We think, for example that the table continues to exist when we are not perceiving it, and that the same table is publicly available to more than one perceiver at a time. This makes it clear that a table is something over and above the sense-data that appear to any given subject of experience. But if there were no table existing independently of us in space we should have to formulate a complicated hypothesis about there being as many different seeming-tables as there are perceivers, and explain why nevertheless all the perceivers talk as if they were perceiving the same object. 
But note that on the sceptical view, as Russell points out, we ought not even to think that there are other perceivers either, for if we cannot refute scepticism about objects, we are as badly placed to refute scepticism about other minds.

Russell short-circuits the difficulty by accepting a version of the argument to the best explanation. It is simpler and more powerful, he argues, to adopt the hypothesis that, first, there are physical objects existing independently of our sensory experience, and, secondly, that they cause our perceptions and therefore 'correspond' to them in a reliable way. Following Hume, Russell regards belief in this hypothesis as 'instinctive'.

To this, he argues, we can add another kind of knowledge, namely, a priori knowledge of the truths of logic and mathematics. Such knowledge is independent of experience, and depends only on the self-evidence of the truths known. When perceptual knowledge and a priori knowledge are conjoined they enable us to acquire general knowledge of the world beyond immediate experience, for the first kind of knowledge gives us empirical data and the second permits us to draw inferences from it.

These two kinds of knowledge can each be further divided into subkinds, described by Russell as immediate and derivative knowledge respectively. He gives the name 'acquaintance' to immediate knowledge of things. The objects of acquaintance include particulars, that is, individual sense-data (and perhaps ourselves), and universals. Derivative knowledge of things Russell calls 'knowledge by description', which is general knowledge of facts made possible by combination of and inference from what we are acquainted with.

Immediate knowledge of truths Russell calls 'intuitive knowledge', and he describes the truths so known as self-evident. These are propositions which are just 'luminously evident, and not capable of being deduced from anything more evident'. For example, we just see that ' $1+1=2$ ' is true. Among the items of intuitive knowledge are reports of immediate experience; if I simply state what sense-data I am now aware of, I cannot (barring trivial slips of the tongue) be wrong.

Derivative knowledge of truths consists of whatever can be inferred from self-evident truths by self-evident principles of deduction.

Russell concedes that despite the appearance of rigour introduced by the availability of a priori knowledge, we have to accept that ordinary general knowledge is only as good as its foundation in the 'best explanation' justification and the instincts which render it plausible. Ordinary knowledge amounts at best therefore to 'more or less probable opinion'. But when we note that probable opinions form a coherent and mutually supportive system - the more coherent and stable the system, the greater the probability of the opinions forming it - we see why we are entitled to be confident in them.

An important feature of Russell's theory concerns space, and particularly the distinction between the allembracing public space assumed by science, and the private spaces in which the sense-data of individual perceivers exist. Private space is built out of the various visual, tactual and other experiences which a perceiver co-ordinates into a framework with himself at the centre. But because we do not have acquaintance with the public space of science, its existence and nature is a matter of inference.

\section{IV}

Thus Russell's first version of a theory of knowledge, and because its chief outlines are found in PP it is the one most familiarly associated with his name. But he was by no means content with the expression of it in PP, which after all was a popular book and did not essay a rigorous exposition of its theses. The technical papers, TK and OKEW which followed were his considered versions of these same questions, and mark an advance over this first sketch. One difference between the theories of PP and OKEW is that Russell had come to see that the experiencing subject's basis for knowledge - the sense-data that appear to him alone, and his intuitive knowledge of the laws of logic - is insufficient as a starting point. He accordingly placed greater weight on an experiencer's memories, and his grasp of spatial and temporal relations holding among the elements of occurrent experience. The subject is also empowered to compare data, for example as to differences of colour and shape. Ordinary common beliefs, and belief in the existence of other minds, are still excluded.

This appeal to an enriched conception of cognitive capacities required at the foundations of knowledge is almost invariably made by empiricist epistemologists - consider Locke and Ayer also - when the thin beams of sensory experience and inference are found, as they invariably are, to be insufficient to bear the weight of knowledge.

With this enriched basis of what he now called 'hard data' Russell reformulated the question to be answered thus: 'can the existence of anything other than our own hard data be inferred?' His approach was first to show how we can construct, as an hypothesis, a notion of space into which the facts of experience - both the subject's own and those he learns by others' testimony - can be placed. Then, to see whether we have reason for believing that the spatial world is real, Russell gives an argument for believing that other minds exist, because if one is indeed entitled to believe this, then one can rely on the testimony of others, which, jointly with one's own experience, will underwrite the view that there is a spatial (a real) world.

This strategy is ingenious. In 'The Relation of Sense-Data to Physics' Russell adds an equally ingenious way of thinking about the relation of sense-experience to its objects. In PP he had said that we infer the existence of physical things from sense-data; now he described them as functions of or 'constructions' out of sensedata. This employs the technique of logic in which a thing of one (more complex) kind can be shown to be 
analysable into things of another (simpler) kind. Russell was here relying on what he called the 'supreme maxim of scientific philosophising', namely the principle that 'wherever possible, logical constructions are to be substituted for inferred entities.' Concordantly with this principle, physical objects are to be analysed as constructions out of sense-data - but not out of actual or occurrent sense-data only, but out of possible sense-data too. For actual and possible sense-data Russell coined the term 'sensibilia' by which is meant 'appearances' or, in Russell's phrase, 'how things appear', irrespective of whether they constitute sense-data currently part of any perceiver's experience. This is intended to explain what it is for an object to exist when not being perceived.

An important aspect of this view, Russell now held, is that sensibilia are not private mental entities, but part of the actual subject-matter of physics. They are indeed 'the ultimate constituents of the physical world', because it is in terms of them that verification of common-sense and physics ultimately depends. This is important because we usually think that sense-data are functions of physical objects, that is, exist and have their nature because physical objects cause them; but verification is only possible if matters are the other way round, with physical objects as functions of sense-data. This theory 'constructs' physical objects out of sensibilia; the existence of these latter therefore verifies the existence of the former.

\section{V}

Such was the epistemology Russell developed in the period to 1914. Instead of developing this distinctive theory further, Russell abandoned it. In later work, particularly AMt and HK, he reverted to treating physical objects, and the space they occupy, as inferred from sense-experience. A number of considerations made him do this. One was his acceptance of the standard view offered by physics and physiology that perception is caused by the action of the environment on our sensory surfaces. 'Whoever accepts the causal theory of perception,' he wrote (AMt p 32), 'is compelled to conclude that percepts are in our heads, for they come at the end of a causal chain of physical events leading, spatially, from the object to the brain of the percipient'. In AMi he gave up talk of 'sense-data', and ceased to distinguish between the act of sensing and what is sensed. His reason for this relates to his acceptance - long in coming, for he had repeatedly resisted it in print - of James's 'neutral monism'.

Another reason for Russell's abandonment of the sensibilia theory was the sheer complexity and, as he came to see it, implausibility of the views he tried to formulate about private and public spaces, the relations between them, and the way sensibilia are supposed to occupy them. He makes passing mention of this cluster of problems in MPD, before there reporting, as his main reason for abandoning the attempt to construct 'matter out of experienced data alone,' that it 'is an impossible programme ... physical objects cannot be interpreted as structures composed of elements actually experienced' (MPD p 79). This last remark is not strictly consistent with Russell's stated view in the original texts that sensibilia are not, and do not have to be, actually sensed; MPD gives a much more phenomenalistic gloss to the theory than it originally possessed. But it touches upon a serious problem with the theory: which is that it is at least problematic to speak of an 'unsensed sense-datum' which does not even require - as its very name seems per contra to demand - an intrinsic connection to perception.

In these early endeavours Russell gave only passing attention to other important questions in epistemology which he later, by contrast, came to emphasise. They concern the kind of reasoning traditionally supposed to be the mainstay of science, namely, non-demonstrative inference. It was some years before Russell returned to consider these questions: the main discussion he gives is to be found in $\mathrm{HK}$, but promissory notes are issued in AMt and IMT.

Acceptance of James's 'neutral monism' was an important turning point. Summarily stated, James's theory is that the world ultimately consists neither of mental stuff, as idealists hold, nor material stuff, as materialists hold, nor of both in problematic relation, as dualists hold, but of a neutral stuff from which the appearance of both mind and matter is formed. By Russell's own account, he was converted to this theory soon after finishing LLA. He had written about James's views in 1914, and rejected them; in LLA itself he was more sympathetic, though still undecided; but finally in a paper entitled 'On Propositions' (1919) he embraced the theory, and used it as a basis for AMi.

The question that came to seem key to Russell is whether consciousness is the essence of the mental, given that, in line with traditional views, consciousness is itself taken to be essentially intentional. In light of Russell's difficulties with the multiple relation theory of judgment it is pointful to remember its partial ancestry in Meinong's view that the intentional relation has at least the three elements of act, content and object. In accepting neutral monism Russell was abandoning the irreducible assumptions of any such view. First, he says, there is no such thing as the 'act'. The occurrence of the content of a thought is the occurrence of the thought, and there is neither empirical evidence nor theoretical need for an 'act' in addition. Russell's diagnosis of why anyone might think otherwise is that we say, 'I think so-and-so', which suggests that thinking is an act performed by a subject. But he rejects this, for reasons similar to those advanced by Hume, who held that the notion of the self is a fiction, and that we are empirically licensed to say no more, on occasions of specifying them, than that there are bundles of thoughts.

Secondly, Russell criticises the relation of content and object. Meinong and others had taken it that the relation is one of direct reference, but in Russell's view it is more complicated and derivative, consisting largely of beliefs about a variety of more and less indirect connections among contents, between contents and objects, and among objects. Add to this the fact that, in imagination and non-standard experiences like hallucination, one can have thoughts without objects, and one sees that the content-object relation involves 
many difficulties - not least, Russell says, in giving rise to the dispute between idealists who think that content is more significant than objects, and realists who think objects are more significant than content. (Russell's use of these labels, although standard, is misleading: we should for accuracy substitute the label 'anti-realist' for 'idealist' here; this is because whereas, at bottom, realism and anti-realism are indeed differing theses about the relation of contents to objects, and thus are epistemological theses, idealism is a metaphysical thesis about the nature of the world, namely, that it is ultimately mental in character. This point is frequently missed in philosophical debate, so Russell is in good company. ) All these difficulties can be avoided, Russell claims, if we adopt a version of neutral monism.

In James's view the single kind of 'primal stuff', as he called it, is 'pure experience'. Knowing is a relation into which different portions of primal stuff can enter; the relation itself is as much part of pure experience as its relata.

Russell could not go along with quite all of this. He thought that James's use of the phrase 'pure experience' showed a lingering influence of idealism, and rejected it; he preferred the use made by others of the term 'neutral-stuff', a nomenclatural move of importance because whatever the primal stuff is, it has to be able when differently arranged - to give rise to what could not appropriately be called 'experience', for example stars and stones. But even with this modified view Russell only partially agreed. He thought that is right to reject the idea of consciousness as an entity, and that it is partly but not wholly right to consider both mind and matter as composed of neutral-stuff which in isolation is neither; especially in regard to sensations - an important point for Russell, with his overriding objective of marrying sense to physics. But he insisted that certain things belong only to the mental world (images and feelings) and others only to the physical world (everything which cannot be described as experience). What distinguishes them is the kind of causality that governs them; there are two different kinds of causal law, one applicable only to psychological phenomena, the other only to physical phenomena. Hume's law of association exemplifies the first kind, the law of gravity the second. Sensation obeys both kinds, and is therefore truly neutral.

Adopting this version of neutral monism obliged Russell to abandon some of his earlier views. One important change was abandonment of 'sense-data'. He did this because sense-data are objects of mental acts, which he now rejected; therefore, since there can be no question of a relation between non-existent acts and supposed objects of those acts, there can be no such objects either. And because there is no distinction between sensation and sense-data - that is, because we now understand that the sensation we have in seeing, for example, a colour-patch just is the colour-patch itself - we need only one term here, for which Russell adopts the name 'percept'.

Before accepting neutral monism Russell had objected to it on a number of grounds, one being that it could not properly account for belief. And as noted, even when he adopted the theory it was in a qualified form; mind and matter overlap on common ground, but each has irreducible aspects. Nevertheless what at last persuaded him was the fact, as it seemed to him, that psychology and physics had come very close: the new physics both of the atom and of relativistic space-time had effectively dematerialised matter, and psychology, especially in the form of behaviourism, had effectively materialised mind. From the internal viewpoint of introspection, mental reality is composed of sensations and images. From the external viewpoint of observation, material things are composed of sensations and sensibilia. A more or less unified theory therefore seems possible by treating the fundamental difference as one of arrangement: a mind is a construction of materials organised in one way, a brain more or less the same materials organised in another.

A striking feature of this view is, surprisingly, how idealist it is. Russell had, as noted, charged J ames with residual idealism. But here he is arguing something hardly distinguishable: that minds are composed of sensed percepts-viz. sensations and images-and matter is a logical fiction constructed of unsensed percepts. Now Russell had often insisted (using his earlier terminology) that sensibilia are 'physical' entities, in somewhat the sense in which, if one were talking about an item of sensory information in a nervous system, that datum would be present as impulses in a nerve or activity in a brain. But then nerves and brains, as objects of physical theory, are themselves to be understood as a constructions from sensibilia, not as traditionally-understood 'material substance', the concept of which physics has shown to be untenable. At the end of AMi ( pp 305, 308) Russell accordingly says that 'an ultimate scientific account of what goes on in the world, if it were ascertainable, would resemble psychology rather than physics ... [because] psychology is nearer to what exists'. This explains Russell's notorious claim that 'brains consist of thoughts' and that when a physiologist looks at another person's brain, what he 'sees' is a portion of his own brain (Schilpp p 705).

For robuster versions of materialism this aspect of Russell's view is hard to accept. But it is not the only difficulty with his version of neutral monism. Not least among others is the fact that he failed in his main aim, which was to refute the view that consciousness is essential to the distinction between mental and physical phenomena. He had not of course attempted to analyse consciousness quite away; his aim was rather to reduce its importance to the mind-matter question. But images, feelings and sensations, which play so central a role in his theory, stubbornly remain conscious phenomena, whereas the sensibilia (by definition including unsensed sensa) which constitute the greater part of matter are not. Russell accepted this, but tried to specify a criterion of difference which did not trade on these facts, namely, the criterion of membership of different causal realms. But whereas that difference is open to question - and even if it exists might be too often hard to see - the consciousness difference is clear-cut. Relatedly, the intentionality which characterises consciousness cannot be left out of accounts of knowledge; memory and perception are inexplicable without it. Russell later acknowledged this point, and gave it as a reason in MPD for having to return to the question of perception and knowledge in later writings.

He also later came to abandon the idea - anyway deeply unsatisfactory from the point of view of a theory supposed to be both neutral and monist - that images and feelings are essentially mental, that is, not wholly 
reducible to neutral-stuff; for in a very late essay he says, 'An event is not rendered either mental or material by any intrinsic quality, but only by its causal relations. It is perfectly possible for an event to have both the causal relations characteristic of physics and those characteristic of psychology. In that case, the event is both mental and material at once'. This, for consistency, is what he should have argued in AMi itself, where only sensations have this character.

But this view in turn generates another problem, which is that it comes into unstable tension with a view to which Russell returned after AMi, namely, that the causes of percepts are inferred from the occurrence of the percepts themselves. As noted earlier, Russell wavered between treating physical things as logical constructions of sensibilia and as entities inferred as the causes of perception; he held this latter view in PP and returned to it after AMi. But on the face of it, one is going to need a delicate connection between one's metaphysics and one's epistemology in order to hold both that minds and things are of one stuff, and that things are the unknown external inferred causes of what happens in minds. So those parts of the legacy of AMi which remain in his later thinking raise considerable difficulties for his views there about matter.

\section{VII}

One of the chief reasons for Russell's reversion to a realistic, inferential view about physical things was the difficulty inherent in the notion of unsensed sensa or, in the later terminology, percepts. As noted above, the idea had been to replace inferred entities with logically constructed ones. If physical things can be logically constructed out of sensibilia, then two desiderata have been realised simultaneously: the theory is empirically based, and inferred entities have been shaved away by Ockham's Razor. But it is obvious that the idea of unsensed sensa (or unperceived percepts) is, if not indeed contradictory, at least problematic. It makes sense - although, without a careful gloss, it is metaphysically questionable - to talk of the existence of possibilities of sensation; but to talk of the existence of possible sensations arguably does not (recall Russell's definition of sensibilia as entities having the 'same metaphysical and physical status as sense-data without necessarily being data to any mind'.) If the choice lay between inferred material particulars and nonactual perceptions existing unperceived, it would seem best to accept the former. This is just what Russell himself came to think. But he did not return to the cruder form of inferential realism held in PP; he had something more ingenious - though in the end no more successful - up his sleeve.

Another reason for Russell's reversion to realism was his recognition that the notion of causality is problematic for phenomenalism. Things in the world seem to affect one another causally in ways hard to explain on the mere basis of reports of sense-experience. Moreover, a causal theory of perception is a natural and powerful way of explaining how experience itself arises. In Russell's mature philosophy of science, contained in AMt and HK, he did not opt for a Lockean view which says that our percepts resemble their causal origins, on the ground that we cannot be directly acquainted with things, and therefore cannot expect to know their qualities and relations. Rather, he now argued, changes in the world and our perceptions are correlated, or co-vary, at least for orders of things in the world that our perceptual apparatus is competent to register (we do not, for example, perceive electrons swarming in the table, so there is no associated covariation of world and perception at that level). The correspondence between percepts and things is one of structure at the appropriate level: 'Whatever we infer from perceptions it is only structure that we can validly infer; and structure is what can be expressed by mathematical logic' (AMt 254). And this means that we have to be 'agnostic' about all but the physical world's mathematical properties, which is what physics describes (ibid 270).

Russell had come to think that the best candidate for what is metaphysically most basic in the world is the 'event'. Objects are constructed out of events in the following way: the world is a collection of events, most of which cluster together around a multitude of 'centres' thus constituting individual 'objects'. Each cluster radiates 'chains' of events, which interact with and react upon chains radiating from other centres-among which are perceivers. When a chain interacts with the events constituting the perceptual apparatus of a perceiver, the last link in the chain is a percept. Since everything is ultimately constituted of events, they are in effect the 'neutral-stuff' of which minds and material things are made. Minds are clusters of events connected by 'mental' relations, not least among them memory; otherwise there is no metaphysica difference between mind and matter. Finally, the interrelations of event-chains is what scientific causal laws describe.

This view enabled Russell to formulate the argument he had long been trying to state satisfactorily, namely, that percepts are parts of things. For on this view it is not the case that there are events which constitute things, and then in addition other events which are perceptions of those things; rather, there are just events constituting the object, some of which are percepts - these being the terminal events of the chains radiating from the object which interact with events constituting the perceiver.

This theory is inferential not in the earlier sense in which the causes of percepts, lying inaccessibly beyond a veil of perception, are guessed from the nature of the percepts themselves. Rather, the inference is from certain terminal events, viz. percepts - which are interactions between (using the term heuristically) 'mental' events and that level of structure in the rest of the event-world with which the 'mental' events are capable of interacting - to the clusters and chains of events constituting the world as a whole.

In AMt the core of the theory is the idea that knowledge of the world is purely structural. We know the qualities and relations as well as the structure of percepts, but we know only the structure of external events, not their qualities. This seems somewhat reminiscent of Locke's distinction between primary and secondary qualities, but it is not; Russell is saying that all we can infer from our percepts is the structure of the qualities and relations of things, not the qualities and relations themselves; and that this is the limit of knowledge. 
This theory has a fatal flaw, which was quickly recognised by the mathematician M. H. A. Newman and set out in an article published soon after the appearance of AMt. It is that since our knowledge of the structure of events is not a mere result of our stipulating them, but is manifestly non-trivial, it follows that our inferential knowledge cannot be limited solely to questions of structure. This is because - to put the point by a rough analogy - a number of different worlds could be abstractly definable as having the same structure, and if they were, knowledge of their structure alone could not separate them and in particular could not individuate the 'real' one. If science genuinely consists of discoveries about the world through observation and experiment, the distinction between what we observe and what we infer cannot therefore be collapsed into a distinction between pure structure and qualities.

Russell accepted Newman's point: 'You make it entirely obvious that my statements to the effect that nothing is known about the physical world except its structure are either false or trivial, and I am somewhat ashamed not to have noticed it myself.'

\section{VIII}

As repeatedly noted, the common thread linking Russell's earlier and later views is the aim of securing the move from perception to the objects of physical theory. On his view, this move must either be inferential, in which it takes us from the incorrigible data of sense to something else, or it is analytic, that is, consists in a process of constructing physical entities out of percepts. On the later view just reported, the inference has a special advantage over more usual inferential theories, in that the inference is not from one kind of thing to another, but from one part of something to its other parts.

In his earlier views Russell had accorded primary reality to sense-data and built everything else out of them. On the later view, reality belongs to events as the ultimate entities, and an important change of emphasis was introduced: percepts remain immediate and as certain as anything can be, but they are not construed as having accurately to represent the physical world, which, in the picture offered by science as the most powerful way to understand it, is anyway very different from how it appears.

Crucially, however, there remains a familiar and major problem about whether inferences from perception to the world are secure. A large part of Russell's aim in HK was to state grounds for taking them to be so. Throughout his thinking about the relation of perception and science he was convinced, as his above-quoted remark in the October 1912 letter to Ottoline Morrell shows, that something has to be known independently of experience for scientific knowledge to be possible. Earlier, as noted, he thought that purely logical principles provide such knowledge. But he now saw that logic alone is insufficient; we must know something more substantial. His solution was to say that inference from perception to events is justified in the light of certain 'postulates' which nevertheless state contingent facts about the word. So stated, Russell's view immediately reminds one of Kant's thesis that possession of 'synthetic a priori knowledge' is a condition of the possibility of knowledge in general, a view which Russell robustly dismissed in the Preface to HK. The difference is explained by the tentative and probabilistic account that Russell, in this last major attempt to state a theory of knowledge, felt was all that could be hoped for.

Two features of Russell's approach in HK explain this result. One is that he now thought that knowledge should be understood in 'naturalistic' terms, that is, as a feature of our biological circumstances, taken together with the way the world is constituted. The other is that he had come to make a positive virtue of the fact (which he always otherwise accepted) that contingent knowledge is never certain, but at best merely credible to some degree. This second point enters into the detailed working out of the views in HK. The first makes its appearance whenever Russell needs to justify the justifications which HK attempts to provide for scientific knowledge.

When data have a certain credibility independently of their relations to other data, Russell describes them as having a degree of 'intrinsic' credibility. Propositions having some intrinsic credibility lend support to propositions inferred from them. The chief question then becomes: how do propositions with some measure of intrinsic credibility transfer that credibility to the hypotheses of science? Another way of framing the question is to ask how reports of observation and experiment can function as evidence. This is where Russell's postulates come in.

There are five postulates. The first, 'the postulate of quasi-permanence', is intended to replace the ordinary idea of a persisting thing: 'given any event $A$, it happens very frequently that, at any neighbouring time, there is at some neighbouring place an event very similar to $A$ '. Thus the 'things' of common-sense are analysed into sequences of similar events. The ancestor of this idea is Hume's analysis of the 'identity' of things in terms of our propensity to take a sequence of resembling perceptions to be evidence for a single thing, as when you have perceptions of a rose bush every time you go into the garden, and therefore take it that there is a single persisting rose bush there even when no perceivers are present.

The second, 'the postulate of separable causal lines', states that 'it is frequently possible to form a series of events such that, from one or two members of the series, something can be inferred as to all the other members'. For example, we can keep track of a billiard ball throughout a game of billiards; common-sense thinks of the ball as a single thing changing its position, which according to this postulate is to be explained by treating the ball and its movements as a series of events from some of which you can infer information about the others.

The third is 'the postulate of spatio-temporal continuity', designed to deny 'action at a distance' by requiring that if there is a causal connection between two events that are not contiguous, there must be a chain of 
intermediate links between them. Many of our inferences to unobserved occurrences depend upon this postulate.

The fourth is 'the structural postulate', which states that 'when a number of structurally similar complexes are ranged about a centre in regions not widely separated, it is usually the case that all belong to causal lines having their origin in an event of the same structure at the centre'. This is intended to make sense of the idea that there exists a world of physical objects common to all perceivers. If six million people all listen to the Prime Minister's broadcast on the wireless, and upon comparing notes find that they heard remarkably similar things, they are entitled to the view that the reason is the common-sense one that they all heard the same man speaking over the airwaves.

The fifth and last is 'the postulate of analogy', which states that 'given two classes of events A and B, and given that, whenever both $A$ and $B$ can be observed, there is reason to believe that $A$ causes $B$, then if, in a given case, $A$ is observed, but there is no way of observing whether $B$ occurs or not, it is probable that $B$ occurs; and similarly if $B$ is observed, but the presence or absence of A cannot be observed'. This postulate speaks for itself. (HK 506-12)

The point of the postulates is, Russell says, to justify the first steps towards science. They state what we have to know, in addition to observed facts, if scientific inferences are to be valid. It is not advanced science which is thus justified, but its more elementary parts, themselves based on common-sense experience.

But what is the sense of 'know' here? On Russell's view, the knowing involved in 'knowledge of the postulates' is a kind of 'animal knowing', which arises as habitual beliefs from the experience of interaction with the world and experience in general. It is far from being certain knowledge. 'Owing to the world being such as it is,' Russell says, 'certain occurrences are sometimes, in fact, evidence for certain others; and owing to animals being adapted to their environment, occurrences which are, in fact, evidence of others tend to arouse expectation of those others. By reflecting on this process and refining it, we arrive at the canons of inductive inference. These canons are valid if the world has certain characteristics which we all believe it to have' (HK 514-5). These are the common-sense facts that the postulates in effect embody, and it is in this sense that we 'know' them. They are implied in the inferences we make, and our inferences are by and large successful; so the postulates can be regarded as in a sense self-confirming.

Although Russell thinks of the postulates as something we know a priori, it is clear that their status is odd. They are in fact empirical in one sense, since they either record or are suggested by experience. What gives them their a priori status is that they are treated as known independently of empirical confirmation (except indirectly in practice), rather than as generalisations in need of such justification. In effect Russell selected some general contingent beliefs which are especially useful to have as premises in thinking about the world, and elevated them to the dignity of postulates. Their indirect justification, in turn, is that on the whole they, or the results of their application, work. Allied to the extremely modest ambition Russell has for epistemology in HK this might be enough. But it has no pretensions to be a theory of knowledge as traditionally conceived, nor a rigorous account of non-demonstrative reasoning.

These last remarks suggest why Russell's arguments in HK received little response, much to his disappointment. He recognised well enough that canons of evidence and scientific reasoning are worth investigating only if we can be confident that, if we got them right, they would reliably deliver science. But the most that Russell's argument establishes is that, so far, the general principles on which our empirical thinking relies have been largely successful. But this looks like exactly the kind of unbuttressed inductive inference Russell was anxious to caution against, citing the example of the chicken who, on being fed day after day, grew increasingly pleased with the world - until the day the butcher came.

In particular, we have no guarantee against the possibility that use of the postulates leads to falsehood, either occasionally or in some systematic way. Now this possibility is in effect allowed by Russell in asking very little of epistemology. The complaint must therefore be that the argument in HK is in fact an admission of failure, when taken in the light of the epistemological tradition. Descartes and his successors in modern philosophy raised questions about the nature of knowledge and how we get it precisely so that they could distinguish between some enterprises - alchemy, astrology, and magic, say - and others - chemistry, astronomy, and medicine, say - which differ not merely in the number of genuinely practical applications they offer, but in telling us something true about the world; and where, moreover, the latter fact explains the former, and opens the way to more of both by the same route. Moreover, our ancient prejudices and animal beliefs might be controverted in the process, as indeed happens: for the world depicted by science is remarkably different from the world of common-sense. But Russell in HK says the utility of applications and those same animal habits of belief are the only final justification we can hope for in epistemology. This is very much less than the project of epistemology traditionally aims to achieve, and it is much less than Russell himself hoped to achieve on first launching his epistemological project after PM.

\section{IX}

Russell had charged Kant with a 'Ptolemaic counter-revolution' in the Preface to HK, but it is not clear that HK itself escapes a Ptolemaic tinge. The postulates are expressly not transcendentally necessary framework features in any sense comparable to Kant's categorial concepts, or to any other species of foundational principle. They are in effect rules of thumb, 'distilled' as Russell puts it, from the epistemological pragmatics of common sense, and justified - if that is the right thing to expect them to be - by their manifest utility in scientific enquiry and ordinary life. 
Nevertheless, they prompt two thoughts. One is that a solid argument can be given in favour of strengthening postulates of the kind envisaged by Russell into structural conditions of inquiry. For what are in effect temperamental reasons it was not open to Russell to consider investigating, by means of transcendental arguments, what is required for the possibility of the kind of knowledge in which science consists. No doubt the precipitate of something like the postulates would result; and that is a suggestive thought. Such an argument would be in fact Russellian, because it would follow his example in his earlier epistemological work of seeking the logical distribution of the problem, so to speak, as when, in the 1911-14 work, he distinguished what was logically primitive from what was derived from it, and how both parts of this classification related to one another in the structure they formed.

It is of course no more than a coincidence, but a remarkable one, that at the time Russell was writing HK, Wittgenstein was coming to not dissimilar conclusions in On Certainty - as if they had been travelling different routes and arriving at near-points at the end of the journey. Wittgenstein's late interest in problems of scepticism and knowledge is rather striking in being straightforward workaday philosophy of just the kind he earlier dismissed as fly-in-the-bottle. His interest in epistemology therefore looks like acceptance that philosophical problems are real ones after all, amenable to investigation - and even solution. His contribution is to insist on the internal connection between the concepts of knowing and doubting, and equally to insist that epistemic justification is provided by the conceptual scheme within which talk of knowledge and doubt alone gets content. The similarities between the very late Russell and Wittgenstein lie in the thought that (to put the matter neutrally as between them) a given area of discourse requires that we accept certain things in order to be able to get along in it - the 'grammatical' propositions which key a discourse's sense, in Wittgenstein; the postulates required by inquiry, for Russell. Of course the parallel is not direct, but it is suggestive. 